\title{
REABILITAÇÃO ORAL COM O EMPREGO DE FACETAS
}

\author{
ORAL REHABILITATION WITH THE USE OF FACETS
}

Sérgio Spezzia

Cirurgião Dentista e Mestre em Ciências pela Escola Paulista de Medicina Universidade Federal de São Paulo.

\section{Autor Principal:}

Sérgio Spezzia

Email: sergio.spezzia@unifesp.br 


\section{Resumo}

$\mathrm{Na}$ harmonização facial são executados procedimentos estéticos, visando obter harmonização entre face, dentes e a boca. A harmonização facial tem sido muito valorizada pelos pacientes, sabe-se que nesse contexto existem algumas técnicas, que são disponibilizadas para feitio dos procedimentos estéticos, como: clareamento dental; bichectomia; emprego de ácido hialurônico e o uso das facetas. A harmonização do sorriso é capaz de ser obtida com o recurso restaurador e estético do uso das facetas. $\mathrm{O}$ objetivo do presente artigo foi evidenciar como as facetas podem ser empregadas nos procedimentos de harmonização facial. Facetas constam de restaurações estéticas parciais que podem revestir a porção vestibular e proximal dos dentes, servindo algumas vezes também para revestir as incisais situadas em elementos dentais anteriores das arcadas superior e inferior. Deve haver bom senso e discernimento acerca das indicações e contra indicações por parte do profissional que irá efetuar o uso das facetas, a opção pelo emprego correto poderá acarretar em êxito ou não do procedimento restaurador utilizado para reabilitação oral. A utilização das facetas possibilita desfecho satisfatório frente ao requisito estético e traz benefícios clinicamente, uma vez que almeja-se realizar preparos com o mínimo desgaste possível nesse tipo de tratamento odontológico.

Palavras-chave: Estética. Sorriso. Desgaste dos Dentes.

Keywords: Esthetics. Smiling. Tooth Wear. 


\section{INTRODUÇÃO}

Busca-se empregar técnicas conservadoras, visando obter desfecho estético satisfatório. A odontologia minimamente invasiva almeja intervir com realização de desgaste dentário reduzido, preservando estrutura dentária (DEVIGUS, 2011; SPEZZIA, 2018). Nesse contexto, a Odontologia Estetica intervém, no intuito de promover harmonia aos pacientes, visando instituir benefícios ao seu bem estar pessoal (RUFENACHT, 2003; SANTOS et al., 2016).

Reabilitações orais estéticas exigem aprimoramento de técnica pelo cirurgião dentista, uma vez que a realização desses procedimentos depende e engloba uma somatória de parâmetros para alcançar êxito, envolvendo diagnóstico firmado corretamente; selecionamento pelo profissional de técnica condizente com a situação clínica presente; escolha do material odontológico a ser empregado de forma correta e execução do procedimento odontológico em etapas de maneira sequencial. O tratamento reabilitador deve ser conservador, e possuir cunho clínico voltado para a estética e a função. Existem várias técnicas disponíveis para emprego odontológico, que são baseadas nessas características, dentre elas as utilizadas na confecção de facetas (HIGASHI \& GOMES, 2006; CARDOSO et al., 2011; DA CUNHA, 2013).

A estética do sorriso pode mostrar-se prejudicada por ação de alguns fatores, envolvendo bruxismo; escurecimento dos dentes; maloclusão; cárie dentária e envelhecimento dos dentes, dentre outros. O emprego das facetas nessas situações tende a restabelecer funcional e esteticamente o sorriso dos pacientes (CARDOSO et al., 2011; JÚNIOR \& BARROS, 2011; CARVALHO et al., 2016; VIEIRA et al., 2018).

Facetas constam de restaurações estéticas parciais que podem revestir a porção vestibular e proximal dos dentes, servindo algumas vezes também para revestir as incisais situadas em elementos dentais anteriores da arcada superior e inferior dos pacientes. Sistemas adesivos disponíveis para uso permitem que as facetas permaneçam fortemente aderidas ou unidas aos dentes (BISPO, 2009; CARDOSO et al., 2011).

Alguns benefícios podem ser obtidos com o uso das facetas, tais como: correção do posicionamento; função; forma; textura; formato e retificação de alterações de cor (BISPO, 2009). 
Atualmente a harmonização facial tem sido muito valorizada pelos pacientes, sabe-se que nesse contexto existem algumas técnicas, que são disponibilizadas para feitio dos procedimentos estéticos, como: clareamento dental; bichectomia; emprego de ácido hialurônico e o uso das facetas. $\mathrm{Na}$ harmonização facial são executados procedimentos estéticos, visando obter harmonização entre a face, os dentes e a boca (CARVALHO et al., 2016; GOMES \& SILVA, 2016; MENDES, 2018).

O objetivo do presente artigo foi evidenciar como as facetas podem ser empregadas nos procedimentos de harmonização facial.

\section{REVISÃO DE LITERATURA}

A opção pelo uso de facetas deve ocorrer depois de efetuada uma análise detalhada acerca da escolha do uso desse procedimento, levando em conta se existe perspectiva para obter-se restabelecimento da harmonia e da estética do sorriso. A harmonização do sorriso é capaz de ser obtida com o recurso restaurador e estético do uso das facetas (BISPO, 2009; CARDOSO et al., 2011; CARVALHO et al., 2016; GOMES \& SILVA, 2016; MENDES, 2018).

A confecção das facetas pode ocorrer por intermédio do emprego da técnica direta, onde utiliza-se resina composta e através da técnica indireta, que usa cerâmica ou resina composta indireta para obter as facetas, compondo dessa forma, facetas de resina composta e facetas de cerâmica para utilização clínica. Na técnica direta, no próprio consultório odontológico pode-se confeccionar as facetas, fazendo-se uso da resina composta por sobre os elementos dentais. Já na técnica indireta, lança-se mão do uso de serviços protéticos laboratoriais, ocorrendo sua confecção com uso do cerômero, que consta do uso de resina composta indireta ou com emprego da cerâmica (SOUZA et al., 2002; SILVA, 2005; AQUINO et al., 2009).

As vantagens do emprego de facetas diretas englobam a possibilidade de confeccioná-las numa sessão somente, apresentado custo reduzido. Já as desvantagens envolvem problemas com a estabilidade de cor e a resistência apresentada no decorrer do seu uso clínico em boca (SOUZA et al., 2002).

Relacionado as facetas indiretas, que fazem uso de cerâmica em sua confecção,

têm-se algumas vantagens, como melhores propriedades mecânicas e melhor REVISTA FLUMINENSE DE ODONTOLOGIA - ANO XV - No 52 - Julho / Dezembro 2019 
delineamento da anatomia das próteses, o que pode repercutir na performance apresentada pela vida útil da faceta. Em contrapartida existem algumas desvantagens, como maior desgaste dentário para emprego da técnica e maiores custos para sua obtenção, uma vez que além dos honorários protéticos laboratoriais, têm-se necessidade de realizar algumas consultas ou etapas clínicas odontológicas para desfecho do caso clínico (SOUZA et al., 2002).

Deve haver bom senso e discernimento acerca das indicações e contra indicações por parte do profissional que irá efetuar o uso das facetas, a opção pelo emprego correto poderá acarretar em êxito ou não do procedimento restaurador utilizado para a reabilitação oral (BISPO, 2009).

Constam de possíveis indicações para utilização das facetas, o seu emprego em elementos dentais dotados de cor, forma, posição e tamanho modificados ou alterados; na presença de diastemas; em cárie dentária que ocasione prejuízo na porção vestibular dos dentes; nas anormalidade de forma, abrangendo microdontia, dentes cônicos e malformados; em dentes com amelogênese imperfeita e hipoplasia do esmalte e para reconstrução da dimensão vertical de oclusão, entre outras (CARNEIRO et al., 1996; NOGUEIRA Jr. et al., 2002; SOUZA et al., 2002; BISPO, 2009; PERES, 2010; RIBEIRO et al., 2010; GONZALEZ et al., 2011).

Opta-se por escolher-se materiais odontológicos, visando estética bucal satisfatória, nesse contexto, tais materiais devem possuir propriedades, como: durabilidade; biocompatibilidade; estabilidade de cor; resistência à compressão e coeficiente de expansão térmica similar ao dos dentes (KINA, 2005; HENRIQUES et al., 2008).

Nesse contexto, facetas tem sido frequentemente empregadas na restauração de dentes anteriores, devido a possível obtenção de propriedades satisfatórias com seu uso, como biocompatibilidade, durabilidade e estética (FRADEANI et al., 2005).

O uso das facetas de cerâmica possui vantagens, como: elevada resistência adesiva; propriedades estéticas satisfatórias; coeficiente de expansão térmica similar ao dos dentes; disponibilidade de vários sistemas cerâmicos para utilização e escolha e resistência a ataques eletrolíticos e de origem química na cavidade bucal, entre outras. Em contrapartida, convive-se com alguns problemas para seu uso, tais como: confecção realizada dispendendo maior período; maiores gastos para sua obtenção; elementos 
dentais antagonistas que podem apresentar desgaste em decorrência; necessita-se empregar próteses provisórias, entre etapas clínicas de sua confecção; cimentação adesiva pode ocorrer somente com materiais indicados e necessidade de aperfeiçoamento prévio dos cirurgiões dentistas que irão aplicar essa técnica, dentre outras (MONDELLI et al., 2003; BISPO, 2009).

Facetas de resina composta tem como vantagens: pequena abrasividade; maior resiliência; manuseio descomplicado; menores gastos para sua obtenção; possível realização do procedimento numa sessão e inexistência de requisição de serviços protéticos laboratoriais, entre outras. Os problemas para emprego de facetas de resina composta, podem englobar, presença de porosidade; possível infiltração marginal aumentada; resistência baixa; pouca resistência frente ao desgaste e instabilidade na cor, dentre outras (ALMILHATTI, et al., 2002; PERES, 2010).

\section{DISCUSSÃO}

Convém salientar que as estruturas faciais apresentam-se modificadas em decorrência da idade, devido ao fato, muitos pacientes buscam tratamentos estéticos para minimização do problema, no intuito de obter o retorno de uma aparência dotada de harmonização e rejuvenescida (COIMBRA et al., 2014).

No cômputo geral, a análise estética do sorriso considera a posição, forma, textura e cor dos dentes. Já na análise estética da região dos lábios, fazem-se importantes a posição do lábio inferior e do superior. Deve-se procurar obter uma relação harmoniosa desses parâmetros, visando um desfecho estético favorável (CARVALHO et al., 2016).

Deve-se elaborar um planejamento prévio antes da realização do tratamento estético propriamente dito, respeitando-se as reais expectativas dos pacientes acerca do desfecho desses procedimentos estéticos e o possível desfecho reabilitador estético capaz de ser obtido pelo profissional.

A procura da instalação de harmonia pretende inter-relacionar elementos concomitantemente, buscando desfecho satisfatório, que apenas pode ocorrer, havendo atuação de todas as partes envolvidas. Deve haver domínio do cirurgião dentista que 
executará os procedimentos estéticos, no que tange a determinação do tamanho, forma, cor e linhas dos dentes para que se obtenha êxito (MONDELLI, 2003).

A qualidade de vida dos pacientes é capaz de ser melhorada com o recurso da estética odontológica. Os procedimentos realizados podem promover um relacionamento harmonioso entre face, corpo e mente dos indivíduos. A atuação do cirurgião dentista propicia aprimoramento da estética facial, o que repercute socialmente (PAPAZIAN et al., 2018).

Existe disponibilidade de vários tipos de prótese dentária para uso, entretanto, as facetas estéticas constam de reabilitação protética mais conservadora, que permite manutenção do remanescente dentário (BISPO, 2009).

Em conformidade com Mendes et al., (2004), preparos realizados na confecção das facetas estéticas constam de preparações menos invasivas, que requerem menor desgaste e são mais rapidamente realizadas, comparando-se com preparações executadas convencionalmente para as próteses parciais fixas de coroas totais, por exemplo.

Segundo Souza et al., (2002), facetas indiretas e diretas possuem algumas vantagens, ao efetuar-se uma comparação com as características intrínsecas as coroas totais, dentre elas, citam-se: conservação de estrutura dental; estética superior; melhor resistência à abrasão e menor período dispendido clinicamente para preparação.

\section{CONCLUSÕES}

A utilização das facetas possibilita desfecho satisfatório frente ao requisito estético e traz benefícios clinicamente, uma vez que almeja-se realizar preparos com o mínimo desgaste possível nesse tipo de tratamento odontológico.

\section{REFERÊNCIAS}

1 -Devigus A. Minimally invasive dentistry. Eur J Esthet Dent, 2011; 6(2):123.

2 - Spezzia S. Odontologia minimamente invasiva e tratamento restaurador atraumático. Rev Odontol Planal Cent, 2018; 8(1):38-46.

3- Rufenacht CR. Princípios da integração estética. São Paulo: Quintessence, 2003. 
4- Santos BC, Dantas LF, et al. Odontologia Estética e Qualidade de Vida: revisão integrativa. Ciênc Biol Saúde, 2016; 3(3):91-100.

5- Higashi C, Gomes JC, et al. Planejamento estético em dentes anteriores. In: Miyashita E, Mello AT. Odontologia estética: planejamento e técnica. Artes Médicas; 2006.

6- Cardoso PC, Decurcio RA, et al. Facetas Diretas de Resina Composta e Clareamento Dental: Estratégias para Dentes Escurecidos. Rev Odontol Bras Central, 2011; 20(55):341-7.

7- da Cunha ARFMD. Facetas de Porcelana VS Facetas de Resina Composta. [Dissertação]. Portugal, Porto: Universidade Fernando Pessoa, 2013.

8- Cardoso PC, Cardoso LC, et al. Restabelecimento estético funcional com laminados cerâmicos. ROBRAC, 2011; 20(52):88-93.

9- Júnior B, Barros C. Reabilitação Estética com Faceta Indireta em Porcelana. Rev Odontol Plan Centr, 2011; 2 (1):9-15.

10- Carvalho LGA, Rodrigues GMF, et al. Evaluation of aesthetic perception of the smile by lay people and dental undergraduate students. J Clin Dent Res, 2016; 13(3):6876.

11- Vieira AC, de Oliveira MCS, et al. Abordagem Interdisciplinar na Reabilitação Estética do Sorriso. Rev Odontol Araçatuba, 2018; 39(2):54-9.

12- Bispo LB. Facetas Estéticas: status da arte. Rev Dentística online, 2009; 8(18):11-4.

13- Gomes AFV, Silva LF. A análise qualitativa da percepção da estética e autoestima de pacientes odontológicos. [Trabalho de Conclusão de Curso]. Graduação em Odontologia. Aracaju: Universidade Tiradentes, 2016.

14- Mendes ACN. A Influência da Estética na Saúde Bucal. [Trabalho de Conclusão de Curso]. Porto Velho: Centro Universitário São Lucas, 2018.

15- Silva SB. Facetas diretas de resina composta versus facetas indiretas em porcelana. [Monografia]. Especialização em Dentística Restauradora. Florianópolis: Escola de Aperfeiçoamento Profissional - ABO-Santa Catarina, 2005.

16- Souza EM, Silva e Souza Jr. MH, et al. Facetas estéticas indiretas de porcelana. J Bras Odontol Clin, 2002; 1(3):256-62.

17- Aquino APT, Cardoso PC, et al. Facetas de porcelana: solução estética e funcional. Clin Int J Braz Dent, 2009; 5(2):142-52. 
18- Carneiro ECS, Severo LS, et al.. Facetas laminadas de porcelana: quando e como? In: Todescan FF, Bottino MA. Atualização na clínica odontológica. A prática da clínica geral. São Paulo: Artes Médicas, 1996.

19- Nogueira Jr. L, Teixeira SC, et al. Restabelecimento da estética e função em paciente com amelogênese imperfeita: relato de um caso clínico. J Bras Odontol Clin, 2002; 1(4):275-9.

20- Peres R. Facetas laminadas: Revisão de literatura. [Monografia]. Especialização em Prótese Dentária. Montes Claros: Instituto de Ciências da Saúde - Funorte/Soebras, 2010.

21- Ribeiro LGM. Avaliação da adaptação marginal e interna de facetas cerâmicas confeccionadas por três diferentes métodos. [Tese]. Florianópolis: Universidade Federal de Santa Catarina, 2010.

22- Gonzalez MR, Ritto FP, et al. Falhas em restaurações com facetas laminadas: uma revisão de literatura de 20 anos. Rev Bras Odontol, 2011; 68(2):238-43.

23- Kina S. Cerâmicas dentárias. Rev Dental Press Estética, 2005; 2(2):112-28.

24- Henriques ACG, Costa DPTS, et al. Cerâmicas odontológicas: aspectos atuais, propriedades e indicações. Odontol Clin Cientif, 2008; 7(4):289-94.

25- Fradeani M, Redemagni M, et al. Porcelain laminate veneers: 6- to 12- year clinical evaluation - A Retrospective Study. Int J Period Rest Dent, 2005; 25(1):9-17.

26- Mondelli R, Coneglian E, et al. Reabilitação Estética do Sorriso com Facetas Indirectas de Porcelana. Biodonto, 2003; 1(5):22-43.

27- Almilhatti H, Giampaolo ET, et al. Infiltração marginal em facetas estéticas de resina composta em próteses parciais fixas. PGR, 2002; 5(1):58-63.

28- Coimbra DD, Uribe NC, et al.. "Quadralização facial" no processo do envelhecimento. Surg Cosm Dermatol, 2014; 6(1):65-71.

29- Mondelli J. Estética e cosmética em Clínica Integrada Restauradora. 1ª ed. São Paulo: Quintessence Editora, 2003.

30- Papazian MF, da Silva LM, et al. Principais aspectos dos preenchedores faciais. Rev Faipe, 2018; 8(1):101-16.

31- Mendes P, Bonfante G, et al. Facetas laminadas- Cerâmica e Resina: Aspectos Clínicos. Artes Médicas, 2004. 